Determination the set-off migration of ink in cardboardcups used in coffee vending machines

Esther Asensio, Teresa Peiro and Cristina Nerín*

Department of Analytical Chemistry, Aragon Institute of Engineering Research I3A, CPS-University of Zaragoza, Torres Quevedo Building, María de Luna 3, 50018 Zaragoza, Spain.

*Corresponding author: Tel: +34 976761873, fax: +34 976762388. Email address: cnerin@unizar.es

E-mail address: (Esther Asensio) estheracounizar.es and (Teresa Peiro) 7015860unizar.es 


\section{Highlights}

- A procedure for the analysis of migrants by HS-SPME-GC-MS for the analysis of cardboard-cups as food contact material has been optimized.

- Migration tests with simulant C (20\% EtOH) and D1 (50\% EtOH) were carried out.

- The use of printed cardboard-cups with the selected beverages can be considered appropriate.

- Migrant compounds from cardboard-cups (ink, pulp wood and LDPE coating) have been identified and quantified 


\begin{tabular}{|c|}
\hline ink \\
\hline cardboard \\
\hline LDPE \\
\hline
\end{tabular}

Food contact material

HS-SPME-GC-MS

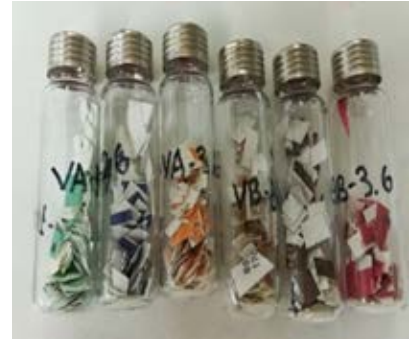

Screening of volatile compounds in cardboard-cups
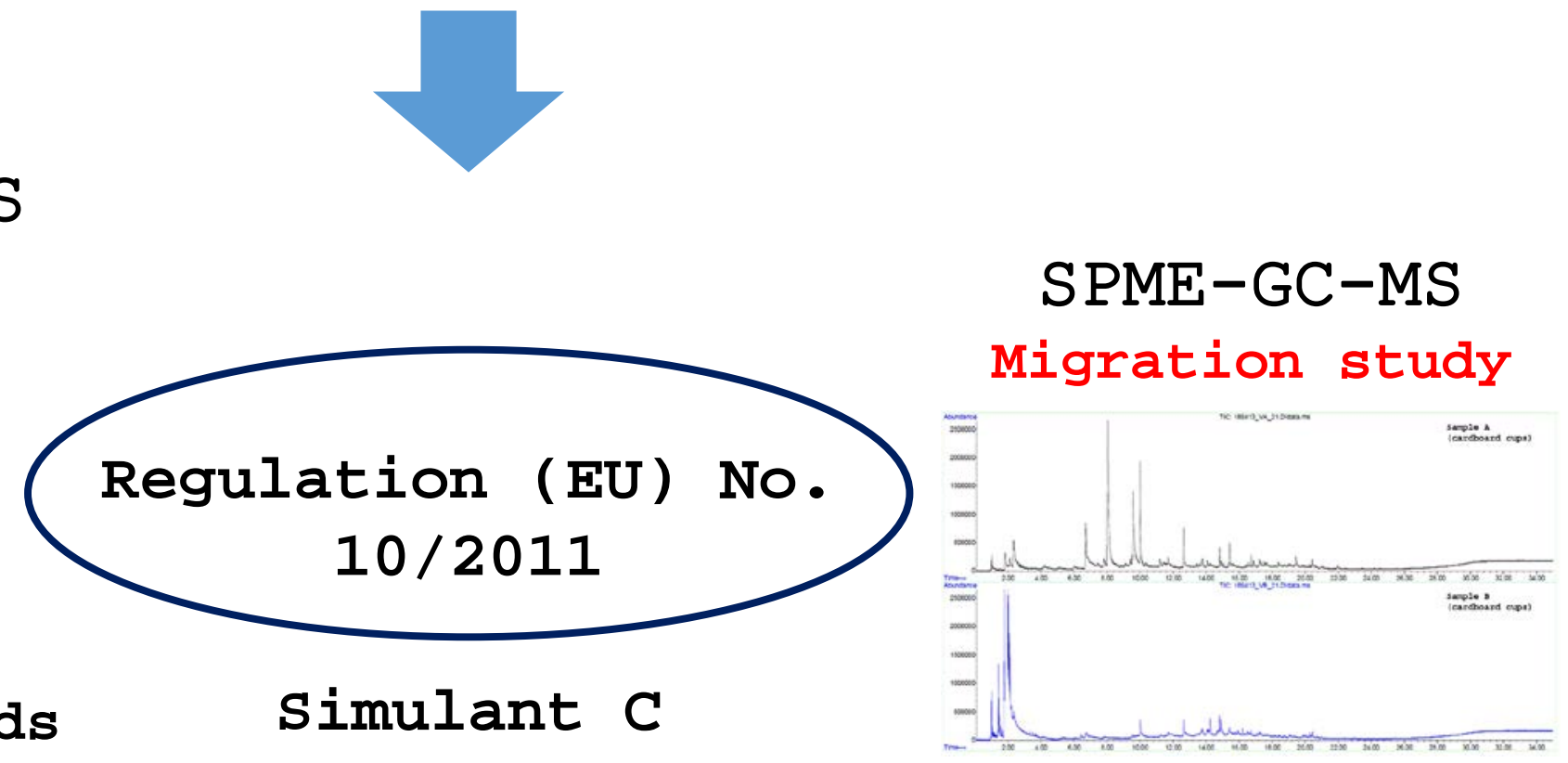

$$
\begin{gathered}
\text { Set-off } \\
\text { (ink transference to } \\
\text { inner side) }
\end{gathered}
$$

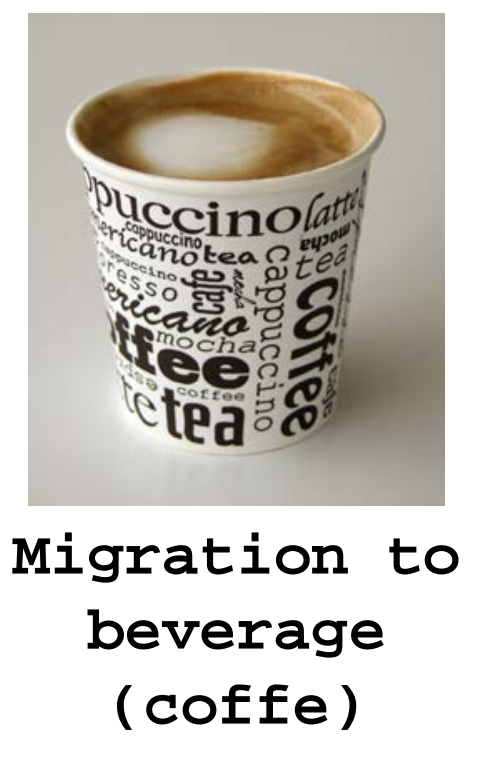

Simulant D1 


\title{
Determination the set-off migration of ink in cardboard- cups used in coffee vending machines
}

Esther Asensio, Teresa Peiro and Cristina Nerín*

\begin{abstract}
The set-off migration from printing inks can cause alterations in the safety and acceptability of food. Therefore, its control in the food industry is of special importance. The aim of this study was the determination of the migration of compounds coming from different types of cardboard-cups used in coffee vending machines. The volatile compounds present in cardboard-cups were studied and specific migration studies were carried out by solid phase microextraction with headspace coupled to gas chromatography (HSSPME-GC-MS). The migration of compounds from the cardboard-cups manufacturing material, plastic coating (LDPE) and printing inks were identified and quantified. Those migrants listed in the Regulation No. 10/2011 presented values lower than the specific migration limit (SML), although a series of non-listed and nonauthorized compounds were identified. From the results obtained the risk assessment of the vending cups from two different companies has been done.
\end{abstract}




\section{Determination the set-off migration of ink in cardboard- cups used in coffee vending machines}

Esther Asensio, Teresa Peiro and Cristina Nerín*

Department of Analytical Chemistry, Aragon Institute of Engineering Research I3A, CPS-University of Zaragoza, Torres Quevedo Building, María de Luna 3, 50018 Zaragoza, Spain.

*Corresponding author: Tel: +34 976761873, fax: +34 976762388. Email address: cnerineunizar.es

E-mail address: (Esther Asensio) estherac@unizar.es and (Teresa Peiro) 7015860unizar.es

\section{Abstract}

The set-off migration from printing inks can cause alterations in the safety and acceptability of food. Therefore, its control in the food industry is of special importance. The aim of this study was the determination of the migration of compounds coming from different types of cardboard-cups used in coffee vending machines. The volatile compounds present in cardboard-cups were studied and specific migration studies were carried out by solid phase microextraction with headspace coupled to gas chromatography (HSSPME-GC-MS). The migration of compounds from the cardboard-cups manufacturing material, plastic coating (LDPE) and printing inks were identified and quantified. Those migrants listed in the Regulation No. 10/2011 presented values lower than the specific migration limit (SML), although a series of non-listed and nonauthorized compounds were identified. From the results obtained the risk assessment of the vending cups from two different companies has been done.

Keywords: cardboard, food contact, printing inks, risk assessment, set-off migration, vending cups, NIAS, migration. 


\section{Introduction}

Food and beverages may interact strongly with the materials that they touch and this is specially important in vending machines, where often the contact is at high temperature. These interactions may result in migration of substances from the food contact materials to the beverages, affecting both the odour, quality of food as well as the health of consumers (Aznar et al., 2015, 2016; Clemente et al., 2016; Domeño et al., 2017).

The consumption of hot drinks (coffee, coffee with milk, etc.) from vending machines has become a common practice in the workplace and leisure. Although the potential migration is very high with the materials currently used in vending machines, very few studies have been performed to demonstrate the safety in use of these materials. In this type of machines, the cups, usually made of cardboard with a plastic coating and printed on the outside, are stacked inside the dispensing machine until the customer buys the product. Set-off migration can occur when the cartons are stored in rolls, or when the paper cups are stacked one inside the other. In these conditions, the set-off phenomena causes the migration of compounds from the container itself to the product, that is, to the hot beverage.

Printing inks are mixtures of chemical compounds, usually applied on the outer side of FCM (Food Contact Material). Among them, ultraviolet (UV) curable inks are mixtures made of resins or oligomers, pigments, additives, monomers and photoinitiators, which are responsible for absorbing the UV energy, forming reactive species capable of initiating a chain reaction (Lago at al., 2015; Brionisio-Lemos et al., 2017). The presence of printing ink components coming from food packaging into food is a subject of 
concern, that caused a Rapid Alert System for Food and Feed (RASFF) in September 2005, when 2-isopropylthioxanthone (ITX), a photoinitiator present in UV-cured inks, was detected in baby milk (RASFF, 2005).

Paper and cardboard are porous materials, where chemicals can migrate from the outside through the packaging. Printing inks have been shown to migrate through paper and cardboard to dry and liquid foods simulants (Suciu et al., 2013; Cai et al., 2017; Rosenmai et al., 2017). The large pore size of the paper-derived materials allows the migration of the smaller molecules from the outside to the inside of the food. The use of barrier materials can significantly reduce food contamination by direct transference, but the set-off phenomena still remains.

As food contact materials, paper \& board are not harmonized in European legislation. The resolution approved by the Council of Europe established the rules to apply to paper and board for food contact (RESAP, 2005), but the general requirements established by the frame Regulation (EC) 1935/2004 apply to any FCM: they should not transfer their constituent to foodstuffs in quantities that could endanger human health or bring about an unacceptable change in the composition of the foodstuffs or a deterioration in the sensory characteristics. In other words, migration of potential harmful or detrimental substances from paper into foods should be avoided or below limits of concern (Guazzotti et al., 2015).

It has been demonstrated that not only intentionally added compounds, such as monomers, antioxidants or plasticizers, migrate to food but also non-intentionally added substances (NIAS) that can arise from different origins (Aznar et al., 2012; Nerín et al., 2013). Therefore, the analysis that allows the identification of 
NIAS is as important as the performance of a target analysis of the known additives. Therefore, its control in the food industry through global and specific migration studies is of special importance.

Migration studies and set-off determination from printing inks require sensitive analytical procedures to identify every single compound coming from the material. For volatile substances, GC-MS is the most used technique, although the combination with SPME would be often needed to enhance the sensitivity (Peters et al., 2019). The aim of this work is to study the migration of compounds coming from different types of cardboard-cups used in coffee vending machines. In order to fulfill this objective, migration studies were done. Subsequently, specific migration analysis were carried out by SPME-GC-MS. Then, the volatile compounds coming from the cups were identified and the pattern recognition was done, identifying those coming from set-off of printing inks. From the results obtained risk assessment of the vending cups was done.

\section{Material and methods}

\subsection{Chemicals and analytical standards}

Analytical standards used for quantification were bought in SigmaAldrich (Barcelona, Spain): 2,6-ditert-butylcyclohexa-2,5-diene1,4-dione (CAS 719-22-2); 3,5-ditert-butyl-4-hydroxy benzaldehyde (CAS 1620-98-0); 2,6-di(propan-2-yl)naphthalene (CAS 24157-81-1), tributyl 2-hydroxypropane-1,2,3-tricarboxylate (CAS 77-94-1), methyl hexadecanoate (CAS 112-39-0); 2,6-ditert-butyl-4methylphenol (CAS 128-37-0); 1-hexadecanol (CAS 29354-98-1); tributyl acetylcitrate (CAS 77-90-7); alpha-methylstyrene (CAS 9883-9); 2-ethyl,1-hexanol (CAS 104-76-7) and benzophenone as 
internal standard(CAS 119-61-9). Ethanol was purchased from Scharlab (Madrid, Spain) and sodium chloride from Panreac (Barcelona, Spain).

All stocks solutions of the analytical standards were prepared at a concentration of $1000 \mu \mathrm{g} / \mathrm{g}$ in ethanol. The working solutions of all the compounds were diluted to 20\% ethanol. $10 \mu \mathrm{L}$ of an internal standard solution (1000 $\mu \mathrm{g} / \mathrm{g})$ were added to all working solutions and samples. All solutions and calibrants were under gravimetric control.

\subsection{Samples}

For the development of this study, two different types of cardboard-cups were selected, provided by two different companies that offer hot beverages in vending machines. Throughout the work, reference will be made to type A cups (company 1) and type B cups (company 2). Both types of cups are made of cardboard with the outer-side printed with the company's drawings and covered inside by a plastic film: Low-Density Polyethylene (LDPE), indispensable for its food use.

\subsection{Screening of volatile compounds in cardboard-cups by HS-SPME- GG-MS}

Before the specific migration tests, the volatile compounds present in the cardboard-cups were analyzed. Canellas et al. (2016) and Domeño et al. (2017) used SPME coupled to GC-MS either by headspace (HS) or by direct immersion to identify volatile compounds in plastic packaging materials, respectively. Similar procedure was attempted here. 
For screening the volatile compounds present in the samples, the area of the cardboard-cup that is always in contact with the beverage was selected. This area was $25.42 \mathrm{~cm}^{2}$, corresponding to $1.3 \mathrm{~g}$ of cardboard. It was cut into pieces of approx. $0.5 \mathrm{~cm}^{2}$, and introduced in vials of $20 \mathrm{~mL}$ for further analysis.

Each sample (A and B) was analyzed by HS-SPME-GC-MS using three different fibers: DVB/CAR/PDMS fiber (50/30 $\mu \mathrm{m})$, PDMS fiber (100 $\mu \mathrm{m})$ and $\mathrm{PA}$ fiber $(85 \mu \mathrm{m})$ and two capillary columns: $\mathrm{HP}-5 \mathrm{MS}(30 \mathrm{~m} \mathrm{x}$ $0.25 \mu \mathrm{m} \times 250 \mu \mathrm{m})$ and BP-20 (30 m x $0.25 \mu \mathrm{m} \times 250 \mu \mathrm{m})$ from Agilent Technologies (Madrid, Spain).

GC-MS (Agilent 6890N with a mass spectrometer MS 5975B detector) coupled to the HS-SPME system (CTC Analytics CombiPal autosampler) was used for each capillary column. The conditions used for the HSSPME study were as follows: incubation time $2 \mathrm{~min}$, temperature 80 ${ }^{\circ} \mathrm{C}$, extraction time $15 \mathrm{~min}$ and desorption time $2 \mathrm{~min}$ (Canellas et al., 2016). The oven program was $50{ }^{\circ} \mathrm{C}$ for $5 \mathrm{~min}$, with rate of 10 ${ }^{\circ} \mathrm{C} / \mathrm{min}$ up to $300{ }^{\circ} \mathrm{C}$, maintained $5 \mathrm{~min}(\mathrm{HP}-5 \mathrm{MS})$ and up to $200{ }^{\circ} \mathrm{C}$, maintained $10 \mathrm{~min}(\mathrm{BP}-20)$. In both cases it was acquired in SCAN mode $(\mathrm{m} / \mathrm{z}=50-600)$. The identification of volatile compounds was carried out using the NIST Chemistry WebBook spectrum library present in the equipment software. All the analyses were carried out by triplicate.

\subsection{Migration tests}

Two types of the most consumed hot beverage cups in vending machines were selected "gourmet long coffee" and "gourmet coffee latte". Then the appropriate food simulants for the migration study and the parameters of the migration for each type of product, established in Regulation (EU) No. 10/2011 were selected. 
Temperature and $\mathrm{pH}$ value of the two types of coffee selected (coffee and coffee latte), immediately after being dispensed by the vending machine, were measured using a portable pH meter with temperature probe $(\mathrm{pH} \&$ Ion-meter GLP 22, Crison, Barcelona, Spain). In both cases, they showed a $\mathrm{pH}>4.5$. As coffee is consumed at a temperature between $40{ }^{\circ} \mathrm{C}$ and $70{ }^{\circ} \mathrm{C}$ and that it does not require a subsequent storage time, according to Chapter 2.1.3 of Regulation (EU) No. 10/2011, 2 h at $70{ }^{\circ} \mathrm{C}$ were selected as contact conditions with food simulants.

According to Annex III of Regulation (EU) No. 10/2011, ethanol 20\% (simulant C) and ethanol 50\% (simulant D1) were used as simulants. In both cases, cardboard-cups were filled with $50 \mathrm{~mL}$ of the corresponding simulant ( $\mathrm{C}$ and D1) according to the rate $6 \mathrm{dm}^{2}$ contact surface/kg of simulant established by the Regulation (EU) No. 10/2011. Then, they were placed into sealed glass jars and the set was introduced in the oven at $70{ }^{\circ} \mathrm{C}$ for 2 hours. A blank of each simulant was prepared and run under the same conditions. The migration tests were carried out by triplicate.

\subsection{Migration study by SPME-GC-MS analysis}

To optimize the SPME conditions three variables were studied: extraction temperature range 60-80 ${ }^{\circ} \mathrm{C}$, extraction time range 15-30 min and type of fiber (DVB/CAR/PDMS and PDMS). In all cases, a stirring of $500 \mathrm{rpm}, 2 \mathrm{~min}$ incubation time and desorption time of 2 min were used. The chromatographic conditions (GC-MS) were those described in section 2.3. The simulants (C and D1) were analyzed after the exposure. 
Prior to SPME, the simulants were allowed to reach room temperature. For the samples tested with simulant C (20\% EtOH), a $20 \mathrm{~mL}$ vial was completely filled and $2 \mathrm{~g}$ of sodium chloride (NaCl) were added. In the case of samples with simulant D1, the use of SPME fibers did not provide good results as the percentage of EtOH was too high. To overcome this problem, it was diluted to 20\% ethanol with distilled $\mathrm{H}_{2} \mathrm{O}$ before the analysis. The SPME analysis wascarried out using $20 \mathrm{~mL}$ vial completely filled with simulant and in the optimized conditions.

Qualitative analysis of the volatile compounds was carried out using the library mass spectra, in order to select the optimal conditions for the identification of those compounds of interest coming from migration of inks present in cardboard-cups studied (Clemente et al., 2016; Lago \& Ackerman, 2016; García-Ibarra et al., 2018) or those having specific migration limits (LME) according to Regulation (EU) No. 10/2011. Mass spectra were required to match the standard's top three ions and the percentage of NIST library match (> 85\% automatically match).

\section{Results and discussion}

\subsection{Screening of cardboard-cups by HS-SPME-GG-MS}

The HS-SPME-GC-MS screening analysis of the cardboards-cups studied provided chromatograms with many different peaks according to the type of sample (Fig. 1). The identification of volatile compounds was carried out by using NIST Chemistry WebBook (05 version). It can be seen that the chromatographic profiles of both cardboardcups were quite different, showing the presence of different compounds from the manufacturing material (cardboard), plastic coating (LDPE) and printing inks. As it has been described 
previously in the introduction, not only the intentionally added substances used must be controlled, but also the NIAS, that can be generated by the processes described and also during the curing of inks. This work has been focused on the identification of these substances, both in the food contact material and in the migration tests.

Confirmation of some compounds was performed after injection of the respective pure standards. Confirmed and tentatively identified volatile compounds with the best matches found during the library search are listed in Table 1.

Those compounds without experimental data of toxicity (NOAEL) and no present in the positive list of EU regulation 10/2011 were classified using the TTC (Threshold of Toxicological Concern) and Cramer rules. The data are also included in Tables 1 and 2.

A series of compounds present in Regulation (EU) No. 10/2011 and related to the plastic film (LDPE) coating of the samples were identified. Also some compounds such as benzaldehyde, butylhydroxytoluene (BHT), phenol and benzoic acid, usually employed in printing inks, were found in both samples. Styrene, $\alpha-$ methylstyrene, 2-ethyl,1-hexanol and 1-decanol were found only in cardboard-cups from sample A. On the other hand, 1,3-dioxolane, 1hexadecanol (adhesive in food packaging), acetyltributyl citrate (ATBC) ( SML applied to the group of substances $60 \mathrm{mg} / \mathrm{kg}$ ) and bis $(2-$ ethyl hexyl)phthalate $(\mathrm{SML}=1.5 \mathrm{mg} / \mathrm{Kg})$ were found in samples $\mathrm{B}$. ATBC as plasticizer is the most abundant compound together with phthalates found in plastic packaging materials (García-Ibarra et al., 2018).

Lago \& Ackerman (2016) identified compounds related to the migration of inks, which were also found in the samples under 
study: nonanal (solvent) and 1-phenyl-1,2,3,4-tetrahydronaphthalene (co-monomer) identified in both food-contact side and outer printed side; $\alpha$-methylstyrene (monomer) identified in printed-side and methyl stearate (slip agent) identified in food contact side.

3,5-di-tert-butyl-4-hydroxybenzaldehyde, metabolite of a food additive butylated hydroxytoluene (BHT), was identified in samples A and was classified as class II, according to cramer rules. Previous studies showed that a second route of decomposition of BHT gives rise to the formation of intermediate alkoxy radicals, which in turn reacts to form predominantly this compound (EFSA, 2012). In both samples, compounds related to the material (pulp wood) used to manufacture the cups (board), such as longicyclene, isolongifolene and longifolene, were also identified (Wang et al., $2004)$

On the other hand, 2-methylsulfonyl acetonitrile and 1-butyl-4-[2(4-ethylphenyl)ethylnyl] benzene were identified in samples $A$ and were classified as class III. Also isophthalic acid di(2fluorophenyl)ester and 2,6-di-tert-butyl-4-hydroxy-methyl-2,5-cyclo hexadien-1-ene were identified in both samples (A and B) and were classified as class III, according to Cramer rules.

The cardboard-cups were analyzed as they are placed in the vending machine. So, most of the compounds identified are probably coming from the set-off migration, either in the roll before making the cups or during the storage of the cups in the vending machine. This work has been focused on identifying this type of migration.

\subsection{Specific migration by SPME-GC-MS analysis}

The best results obtained from SPME optimization were those using DVB/CAR/PDMS fiber, extraction temperature $70{ }^{\circ} \mathrm{C}$, extraction time 
$20 \mathrm{~min}$ and HP-5MS column. Under these conditions the highest number of compounds of interest were identified (García-Ibarra et al., 2018; Domeño et al., 2017; Lago \& Ackerman, 2016; Regulation (EU) No. $10 / 2011)$.

Confirmed and tentatively identified volatile compounds with the best matches found during the library search and specific migration, expressed as $\mathrm{mg} / \mathrm{kg}$ simulant, are shown in Table 3 . In the case of those identified compounds listed in the Regulation EU No. 10/2001, all migration studies showed values below the corresponding SML.

Migration of compounds not listed in EU Regulation No. 10/2011 should be lower than $10 \mathrm{ppb}(\mu \mathrm{g} / \mathrm{kg})$. As can be seen in Table 3, for the quantified compounds, 3,5-ditert-butylphenol and methyl palmitate do not exceed this value, while 2,4-di-tert-butylphenol, tributyl aconitate and tributyl citrate exceed this limit. The first compound has a NOAEL value of $5-20 \mathrm{mg} / \mathrm{kg} \mathrm{bw} / \mathrm{d}$ and a lower value has been quantified. Tributyl aconitate was classified as class I according to the Cramer rules (Toxtree, v3.1.0). For this class, a human exposure threshold of $1800 \mu \mathrm{g} / \mathrm{kg}$ is assigned and this compound was at lower concentration. Tributyl citrate is classified as class III so a human exposure threshold of $90 \mathrm{\mu g} / \mathrm{kg}$ is assigned and sample B presents a lower value for simulant D1. García-Ibarra et al. (2018) carried out studies with packaging samples of printed polypropylene. The migration tests also showed the presence of some compounds identified in this study such as dodecanoic acid, 1-methylethyl ester; isopropyl myristate, tributyl aconitate and tributyl citrate.

Lago \& Ackerman (2016), also identified the same compounds related to the migration of inks, transferred by set-off, in plastic 
packages with an aluminum barrier layer and polyethylene food contact layer. The compounds benzene, 1, 1'-(1,2cyclobutanediyl)bis-,cis- (degradation from antioxidant-class III), methyl palmitate (monomer) in food contact side; 2,4-di-tertbutylphenol (antioxidant degradation compound); naphthalene, 1,2,3,4-tetrahydro-1-phenyl (co-monomer-class III); hexadecanoic acid (degradation from slip agent); octadecanoic acid (monomer/slip agent) and methyl dehydroabietate (from paper) were identified in both printed-side and food contact side. Also the presence of trans-1,2-diphenyl cyclobutane (monomer byproduct-class III), that in this study was identified in samples A with simulant D1, was attributed to set-off migration.

In samples A and B with simulant D1 dehydroabietic acid (DHAA) was identified. Certain FCMs have been reported to contain DHAA and abietic acid ( $A A)$, which can migrate to food simulants from paper and board packaging (Ozaki et al., 2006; Weber et al., 2006; Rosenmai et al., 2017).

The study carried out by Clemente et al. (2016) showed the presence of tributyl aconitate $(0.287-0.395 \mathrm{mg} / \mathrm{kg})$ and 3,5-di-tert-butyl4-hydroxybenzaldehyde $(0.086-0.192 \mathrm{mg} / \mathrm{kg})$ in simulant D1 only in printed multilayer (PE/Al/PP/ink), relating their presence with a possible set-off migration. In this study the first compound was found in higher concentration $(0.978 \mathrm{mg} / \mathrm{kg})$ from sample $\mathrm{B}$ in simulant D1, confirming that the source was the printing ink.

A series of compounds classified as class II according to the Cramer rules were identified in both samples with simulant D1, such as methyl-2-hydroxy-heptadecanoate and 6,10,14-trimethylpentadecan2-one. In sample A with both simulants the 4-phenylazetidin-2-one classified as class III was identified. The following compounds 
were identified in simulant D1 from sample A: 3-methyl-3-phenyl azetidine, 5-methyl-5-(4,8,12-trimethyltridecyl)oxolan-2-one and 1,2-diphenyl prop-2-en-1-one, all of them classified as class III. Among the other compounds identified in migration tests pimaral and pimaric acid, classified as class III respectively, were related with the manufacturing of the cardboard-cups (wood/paper). The presence of 2,6-diisopropyl naphthalene (class III) could be related with recycled paper/cardboard used in the manufacturing of cardboard-cups (Weber et al., 2004; Nerín \& Asensio, 2004, 2007; Asensio \& Nerín, 2009).

\section{Conclusions}

After carrying out the specific migration analysis of cups used in vending machines, using the appropriate simulants according to the intended use and under the test conditions set by Regulation (EU) No. 10/2011, the values obtained did not exceed the limits established by the legislation (SML). Therefore, the use of printed cardboard-cups with the selected beverages "gourmet long coffee" and "gourmet coffee latte" can be considered appropriate. However, it is important to highlight the presence of compounds from both the material of the cardboard-cups (wood pulp) and the plastic coating (LDPE). Several compounds classified as Class II and Class II according to the cramer rules, stand out the importance of the study and the required control of them, while their analysis suggests that this food contact material is unlikely to contribute significantly to dietary Cramer-threshold exceedance. From the study carried out we can conclude that the set-off of printing inks is a reality and an important source of migrants in coffee cardboard-cups used in vending machines. Some of the 
compounds found are not authorized for building food packaging materials. Even though they are coming from printing inks, the contact layer in the cups is LDPE, what makes this structure as a multilayer and then, included in the regulation 10/2011/EU. It is well known that diffusion of low polar organic molecules in LDPE is very fast and consequently the sorpted compounds in direct contact with LDPE can be easily transferred to the food.

\section{Acknowledgements}

The authors acknowledge the funding provided by the Gobierno de Aragón (Spain) to the GUIA group [financiación grupo GUIA T53-17R]. 


\section{References}

Asensio, E., Nerin, C., 2009. Evaluation of a screening method for classifying virgin and recycled paper and board samples. Packaging Technology and Science 22, 311-322. doi:10.1002/pts.855

Aznar, M., Rodriguez-Lafuente, A., Alfaro, P., Nerín, C., 2012. UPLC-Q-TOF-MS analysis of non-volatile migrants from new active packaging materials, Analytical and Bioanalytical Chemistry 404, 1945-1967. doi: $10.1007 / \mathrm{s} 00216-012-6247-5$

Aznar, M., Domeño, C., Nerin, C., Bosetti, O., 2015. Set-off of non volatile compounds from printing inks in food packaging materials and the role of lacquers to avoid migration. Dyes and Pigments 114, 85-92. doi:10.1016/j.dyepig.2014.10.019

Aznar, M., Alfaro, P., Nerin, C., Jones, E., Riches, E., 2016. Progress in mass spectrometry for the analysis of set-off phenomena in plastic food packaging materials. Journal of Chromatography A 1453, 124-133. doi:10.1016/j.chroma.2016.05.032

Canellas, E., Vera, P., Nerin, C., 2016. Multiple headspace-solid phase microextraction for the determination of migrants coming from a self-stick label in fresh sausage. Food Chemistry 197, 24-29. doi:10.1016/j.foodchem.2015.10.039

Brionisio-Lemos, A., Favaro-Perez, M.A., Rossi-Bordin, M., BoseSilva, L., Teixeira-Godoy, H., Padula, M., 2017. Set-off: Development of a simulation press and analytical approach to study the phenomenon. Packaging and Technology and Science 30, 495-504. doi:10.1002/pts.2280

Cai, H., Ji, S., Zhang, J., Tao, G., Peng, C., Hou, R., Zhang, L., Sun, Y., Wan, X., 2017. Migration kinetics of four photo-initiators from paper food packaging to solid food simulants. Food Additives and Contaminants - Part A Chemistry, Analysis, Control, Exposure 
doi:10.1080/19440049.2017.1331470

Clemente, I., Aznar, M., Nerín, C., Bosetti, o., 2016. Migration from printing inks in multilayer food packaging materials by GC-MS analysis and pattern recognition with chemometrics. Food Additives and Contaminants - Part A Chemistry, Analysis, Control, Exposure and Risk Assessment 33,703-714. doi:10.1080/19440049.2016.1155757 Domeño, C., Aznar, M., Nerin, C., Isella, F., Fedeli, M., Bosetti, O., 2017. Safety by design of printed multilayer materials intended for food packaging. Food Additives and Contaminants - Part A Chemistry, Analysis, Control, Exposure and Risk Assessment 34 , 1239-1250. doi:10.1080/19440049.2017.1322221

EFSA CEF Panel (EFSA Panel on Food Additives and Nutrient Sources added to Food). Scientific opinion on the re-evaluation of butylated hydroxytoluene BHT (E 321) as a food additive. EFSA Journal $10(3)$ (2012), p. 2588

Garcia-Ibarra, V., Rodriguez-Bernaldo de Quirós, A., PaseiroLosada, P., Sendon, R., 2018. Identification of intentionally and non-intentionally added substances in plastic packaging materials and their migration into food products. Analytical and Bioanalytical Chemistry 410, 3789-3803. doi:10.1007/s00216-018$1058-y$

Guazzotti, V., Giussani, B., Piergiovanni, L., Limbo, S., 2015. Screening for chemicals in paper and board packaging for food use: Chemometric approach and estimation of migration. Packaging and Technology and Science 28, 385-395. doi:10.1002/pts2109

Lago, M.A., Rodriguez-Bernaldo de Quiros, A., Sendón, R., Bustos, J., Nieto, M.T., Paseiro, P., 2015. Photoinitiators: a food safety 
review. Food Additives \& Contaminants: Part A $1-20$. doi:10.1080/19440049.2015.1014866

Lago, M.A., Ackerman, L.K., 2016. Identification of print-related contaminants in food packaging. Food Additives and Contaminants Part A Chemistry, Analysis, Control, Exposure and Risk Assessment 33, 518-529. doi:10.1080/19440049.2015.1136435

Nerín, C., Asensio, E., 2004. Behaviour of organic pollutants in paper and board samples intended to be in contact with food. Analytica Chimica Acta 508, 185-191. doi: 10.1016/j.aca.2003.11.081 Nerín, C., Asensio, E., 2007. Migration of organic compounds from a multilayer plastic-paper material intended for food packaging. Analytical and Bioanalytical Chemistry 389, 589-596. doi:10.1007/s00216-007-1462-1

Nerín, C., Alfaro, P., Aznar, M., Domeño, C., 2013. The challenge of identifying non-intentionally added substances from food packaging materials: A review. Analytica Chimica Acta 775, $14-24$. doi: $10.1016 / j . a c a .2013 .02 .028$

Ozaki, A., Ooshima, T., Mori, Y., 2006. Migration of dehydroabietic and abietic acids from paper and paperboard food packaging into food- simulating solvents and Tenax TA. Food Additives \& Contaminants 23, 845-860. doi:10.1080/02652030600743813

Peters, R.J.B., Groeneveld, I., Lopez Sanchez, P., Gebbink, W., Gersen, A., de Nijs, M., van Leeuwen, S.P.J., 2019. Review of analytical approaches for the identification of non-intentionally added substances in paper and board food contact materials. Trends in Food Science \& Technology. doi:10.1016/j.tifs.2018.12.010

RASFF, Isopropyl thioxanthone in milk for babies from spain, Alert notification 2005.631, 8 September 2005. 
Regulation (EC) No. 1935/2004 of the European Parliament and of the Council of 27 october 2004 on materials and articles intended to come into contact with food.

Regulation (EU) No. 10/2011 of 14 January 2011 on plastic materials and articles intended to come into contact with food.

Rosenmai, A.K., Bengtström, L., Taxvig, C., Trier, X., Petersen, J.H., Svingen, T., Binderup, M.L., Van Vugt Lussenburg, B.M.A., Dybdahl, M., Granby, K., Vinggaard, A.M., 2017. An effect-directed strategy for characterizing emerging chemicals in food contact materials made from paper and board. Food and Chemical Toxicology 106, 250-259. doi:10.1016/j.fet.2017.05.061

Suciu, N.A., Tiberto, F., Vasileiadis, S., Lamastra, L., Trevisan, M., 2013. Recycled paper-paperboard for food contact materials: Contaminants suspected and migration into foods and food simulant. Food Chemistry 141, 4146-4151. doi:10.1016/j.foodchem.2013.07.014 Wang, S.F., Furuno, T., Cheng, Z., 2004. Chemical composition of raw tall oil from Masson pine pulping. 2nd International Symposium on Technologies of Pulping, Papermaking and Biotechnology on Fiber Plants, Proceedings. Proceedings Paper, 529-534.

Weber, A., vonWright, A., Honkalampi-H€am€al€ainen, U., J€arvinen, M., Lhuguenot, J.C., Severin, I., Dahbi, L., Stammati, A., Zucco, F., Turco, L., Dahlman, O., Bertaud, F., M€aki-Paakkanen, J., Hakulinen, P., Castle, L., Bradley, E., Salkinoja-Salonen, M., Andersson, M., Hoornstra, D., Renn, O., Schweizer, P.J., 2006. Biosafepaper - Application of Bioassays for Safety Assessment of Paper and Board for Food Contact. 
Table 1. Compounds identified and tentatively identified by HS-SPME-GC-MS (HP-5MS) in cardboard-cups with the level of toxicity (TTC) according to Crammer classification and NOAEL values.

\begin{tabular}{|c|c|c|c|c|c|c|c|c|}
\hline \multirow[t]{2}{*}{ Compounds } & \multirow{2}{*}{$\begin{array}{c}\mathrm{RT} \\
(\mathrm{min})\end{array}$} & \multirow[t]{2}{*}{ CAS number } & \multirow{2}{*}{$\begin{array}{c}\mathrm{SML} \\
(\mathrm{mg} / \mathrm{kg})\end{array}$} & \multirow{2}{*}{$\begin{array}{c}\text { NOAEL } \\
(\mathrm{mg} / \mathrm{kg} \mathrm{bw/d})\end{array}$} & \multirow[t]{2}{*}{ Cramer } & \multicolumn{3}{|c|}{$\begin{array}{c}\text { Samples } \\
\text { SPME-fibers }\end{array}$} \\
\hline & & & & & & DVB/CAR/PDMS & PDMS & $\mathrm{PA}$ \\
\hline Dodecane & 8.16 & $112-40-3$ & $N L$ & $>1000$ & & $\mathrm{~A}$ & - & - \\
\hline Undecane & 9.38 & $1120-21-4$ & $N L$ & $>1000$ & & A & - & - \\
\hline Nonanal & 9.63 & $124-19-6$ & $N L$ & & $I$ & A & - & - \\
\hline$\alpha$-methylstyrene $e^{b}$ & 10.50 & $98-83-9$ & 0.05 & & & A & - & - \\
\hline 2-ethyl-1-hexanol ${ }^{b}$ & 11.40 & $104-76-7$ & 30 & & & A & - & - \\
\hline Tridecane & 12.70 & $629-50-5$ & $N L$ & & I & A & - & - \\
\hline Longicyclene & 13.74 & $1137-12-8$ & $N L$ & & I & A & A & - \\
\hline Isolongifolene & 14.00 & $1135-66-6$ & $N L$ & & I & A & A & - \\
\hline Tetradecane & 14.08 & $629-59-4$ & $N L$ & & I & A & - & - \\
\hline Longifolene & 14.22 & $475-20-7$ & $N L$ & & I & $\mathrm{A}, \mathrm{B}$ & $\mathrm{A}, \mathrm{B}$ & - \\
\hline $\begin{array}{l}\text { 2,6-di-tert-butyl-4-hydroxy-4-methyl-2,5- } \\
\text { cyclohexadien-1-one }\end{array}$ & 14.88 & $10396-80-2$ & $N L$ & & III & $\mathrm{A}, \mathrm{B}$ & - & - \\
\hline Butylhydroxytoluene $e^{b}$ & 18.72 & $128-37-0$ & 3 & & & $A, B$ & $A, B$ & A \\
\hline 3,5-di-tert-butyl-4-hydroxybenzal dehyde ${ }^{b}$ & 21.48 & $1620-98-0$ & $N L$ & & II & - & - & A \\
\hline Naphthalene, 1,2,3,4-tetrahydro-1-phenyl & 22.99 & $3018-20-0$ & $N L$ & & III & - & - & A \\
\hline Phthalic acid,hept-4-yl isobutyl ester & 23.46 & NIST356783 & $N L$ & & I & - & - & $\mathrm{A}$ \\
\hline 1 -hexadecanol ${ }^{\mathrm{b}}$ & 23.17 & $36653-82-4$ & c & & & - & - & $\mathrm{B}$ \\
\hline $\begin{array}{l}\text { Benzoic acid, 4-(trans-4-butylcyclohexyl)- } \\
\text {, 4-butoxy-2,3-dicyanophenyl ester }\end{array}$ & 24.24 & $75941-90-1$ & $N L$ & & & - & $\mathrm{A}, \mathrm{B}$ & $\mathrm{A}, \mathrm{B}$ \\
\hline Isophthalic acid, di(2-fluoro phenyl)ester & 24.41 & $\begin{array}{c}\text { NIST } \\
344664\end{array}$ & $N L$ & & III & - & A & - \\
\hline Methyl stearate & 24.94 & $112-61-8$ & $N L$ & 1390 & & - & - & A \\
\hline Acetyltributyl citrate ${ }^{b}$ & 26.27 & $77-90-7$ & $32^{a}$ & & & - & - & B \\
\hline Phthalic acid, di(2-propylpentyl)ester & 28.26 & $70910-37-1$ & $\mathrm{NL}$ & & I & - & - & $A, B$ \\
\hline Bis(2-ethylhexyl) phthalate & 28.28 & $117-81-7$ & 1.5 & & & - & B & - \\
\hline
\end{tabular}

NL not listed in Regulation 10/2011; ${ }^{a}$ SML (T) (group restriction); ${ }^{b}$ Confirmed with standards; ${ }^{\circ}$ Specific migration limit of 60 $\mathrm{mg} / \mathrm{kg}$ (substance for which no specific migration limit by Regulation 10/2011). 
Table 2. Compounds identified and tentatively identified by HS-SPME-GC-MS (BP-20) in cardboard-cups with the level of toxicity (TTC) according to Crammer classification and NOAEL values.

\begin{tabular}{|c|c|c|c|c|c|c|c|c|}
\hline \multirow[t]{2}{*}{ Compounds } & \multirow{2}{*}{$\begin{array}{c}\mathrm{RT} \\
(\mathrm{min})\end{array}$} & \multirow[t]{2}{*}{ CAS number } & \multirow{2}{*}{$\begin{array}{c}\mathrm{SML} \\
(\mathrm{mg} / \mathrm{kg})\end{array}$} & \multirow{2}{*}{$\begin{array}{c}\text { NOAEL } \\
(\mathrm{mg} / \mathrm{kg} \mathrm{bw/d})\end{array}$} & \multirow[t]{2}{*}{ Cramer } & \multicolumn{3}{|c|}{$\begin{array}{c}\text { Samples } \\
\text { SPME-fibers }\end{array}$} \\
\hline & & & & & & DVB/CAR/PDMS & PDMS & $\mathrm{PA}$ \\
\hline 2-propenal & 2.31 & $107-02-8$ & $N L$ & 0.05 & & - & - & A \\
\hline Butane-1,2-diol & 7.07 & $584-03-2$ & $N L$ & 200 & & B & B & - \\
\hline 1,3-dioxolane & 8.25 & $646-06-0$ & 5 & & & B & - & - \\
\hline Styrene & 8.67 & $100-42-5$ & ${ }_{-}^{c}$ & & & - & - & A \\
\hline 2-methylsulfonyl acetonitrile & 7.77 & $2274-42-2$ & $\overline{N L}$ & & III & - & - & A \\
\hline Dodecane & 8.29 & $112-40-3$ & $N L$ & $>1000$ & & A & - & - \\
\hline Cyclooctatetraene & 8.92 & $629-20-9$ & $N L$ & & I & A & - & - \\
\hline$\alpha$-methylstyrene $e^{b}$ & 10.25 & $98-83-9$ & 0.05 & & & A & - & A \\
\hline 2-ethyl-1-hexanol ${ }^{\mathrm{b}}$ & 12.33 & $104-76-7$ & 30 & & & A & - & A \\
\hline Furfural & 12.63 & $98-01-1$ & $N L$ & 36 & & A & - & - \\
\hline Longicyclene & 12.94 & $1137-12-8$ & $N L$ & & I & - & A & - \\
\hline Benzaldehyde & 13.15 & $100-52-7$ & ${ }_{-}^{c}$ & & & $A, B$ & - & - \\
\hline Isolongifolene & 13.28 & $1135-66-6$ & $\overline{N L}$ & & I & A & A & \\
\hline Longifolene & 13.87 & $475-20-7$ & $N L$ & & I & $A, B$ & A & A \\
\hline 2-(2-ethoxyethoxy) ethanol & 14.49 & $111-90-0$ & $3^{a}$ & & I & A & - & - \\
\hline Acetophenone & 14,83 & $98-86-2$ & $N L$ & 75 & & $\mathrm{~A}, \mathrm{~B}$ & - & - \\
\hline 1 -decanol & 16.05 & $112-30-1$ & ${ }^{c}$ & & & A & - & A \\
\hline Butylhydroxytoluene ${ }^{b}$ & 17.60 & $128-37-0$ & $\overline{3}$ & & & A & $\mathrm{A}, \mathrm{B}$ & A \\
\hline 1-butyl-4-[2-(4-ethylphenyl) ethylnyl] benzene & 18.11 & $117392-63-9$ & $N L$ & & III & - & A & - \\
\hline Phenol & 18.53 & $108-95-2$ & - & & & $A, B$ & - & - \\
\hline Isopropyl myristate & 19.03 & $110-27-0$ & $\bar{N} L$ & & I & - & $A, B$ & - \\
\hline Isophthalaldehyde & 19.88 & $626-19-7$ & $N L$ & & I & A & - & - \\
\hline 3-methyl-4-iso propylphenol & 20.53 & $3228-02-2$ & $N L$ & & I & - & A & - \\
\hline $1-(3-e t h y l$ phenyl) ethanone & 20.87 & $22699-70-3$ & $N L$ & & I & $\mathrm{A}, \mathrm{B}$ & - & - \\
\hline 7-acetyl-6-ethyl-1,1,4,4-tetramethyl tetralin & 21.96 & $88-29-9$ & $N L$ & 3 & & $\mathrm{~A}, \mathrm{~B}$ & $\mathrm{~A}, \mathrm{~B}$ & - \\
\hline 3,5-di-tert-butyl-4-hydroxybenzaldehyde ${ }^{b}$ & 22.37 & $1620-98-0$ & $N L$ & & II & A & - & - \\
\hline Hexadecen-1-ol, trans-9 & 22.59 & $64437-47-4$ & $N L$ & & I & - & B & - \\
\hline Naphthalene, 1, 2, 3,4-tetrahydro-1-phenyl & 23.16 & $3018-20-0$ & $N L$ & & III & - & - & A \\
\hline Phthalic acid, hept-4-yl isobutyl ester & 23.49 & NIST356783 & $N L$ & & I & - & B & - \\
\hline Benzoic acid & 23.36 & $65-85-0$ & ${ }_{-}^{c}$ & & & $\mathrm{~A}, \mathrm{~B}$ & - & - \\
\hline 1 -hexadecanol ${ }^{b}$ & 23.58 & $36653-82-4$ & ${ }_{-}^{-}{ }^{c}$ & & & B & - & - \\
\hline
\end{tabular}


Table 3. Compounds identified and tentatively identified in simulants (C and D1) by SPME-GC-MS with the level of toxicity (TTC) according to Crammer rules and NOAEL values.

\begin{tabular}{|c|c|c|c|c|c|c|c|c|}
\hline \multirow{2}{*}{ Compounds } & \multirow{2}{*}{$\begin{array}{c}\mathrm{RT} \\
(\min )\end{array}$} & \multirow{2}{*}{ CAS number } & \multirow{2}{*}{$\begin{array}{c}\mathrm{SML} \\
(\mathrm{mg} / \mathrm{kg})\end{array}$} & \multirow{2}{*}{$\begin{array}{c}\text { NOAEL } \\
(\mathrm{mg} / \mathrm{kg} \mathrm{bw/d})\end{array}$} & \multirow{2}{*}{ Cramer } & \multirow{2}{*}{ Samples } & \multicolumn{2}{|c|}{ Specific migration ( $\mu \mathrm{g} / \mathrm{kg})$} \\
\hline & & & & & & & Simulant C & Simulant D1 \\
\hline$\alpha$-methylstyrene $e^{b, d}$ & 10.44 & $98-83-9$ & 0.05 & & & A & - & $2.86 \pm 0.80$ \\
\hline 2-ethyl, 1-hexanol ${ }^{\text {b,d }}$ & 11.94 & $104-76-7$ & 30 & & & $\begin{array}{l}\text { A } \\
\text { B }\end{array}$ & $\begin{aligned} 61.82 & \pm 6.89 \\
650.98 & \pm 61.22\end{aligned}$ & $\begin{array}{c}82.3 \pm 5.3 \\
-\end{array}$ \\
\hline 2, 4-di-tert-butylphenol ${ }^{b}$ & 18.65 & $96-76-4$ & $N L$ & $5-20$ & & $\begin{array}{l}\mathrm{A} \\
\mathrm{B}\end{array}$ & $\begin{array}{l}17.33 \pm 3.34 \\
243.11 \pm 0.39\end{array}$ & $\begin{array}{l}- \\
-\end{array}$ \\
\hline $\begin{array}{l}\text { Dibutyl,2-methylidene } \\
\text { butanedioate }\end{array}$ & 20.06 & $2155-60-4$ & $N L$ & & I & B & 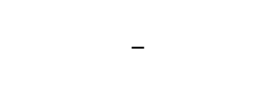 & $\checkmark$ \\
\hline $\begin{array}{l}\text { Dodecanoic acid,1-methyl } \\
\text { ethyl ester }\end{array}$ & 20.42 & $10233-13-3$ & $N L$ & & I & $\begin{array}{l}\mathrm{A} \\
\mathrm{B}\end{array}$ & - & $\begin{array}{l}\checkmark \\
\checkmark\end{array}$ \\
\hline 4-phenylazetidin-2-one & 20.87 & $5661-55-2$ & $N L$ & & II & A & $\checkmark$ & $\checkmark$ \\
\hline $\begin{array}{l}\text { 2,6-diisopropyl } \\
\text { naphthalene }\end{array}$ & 21.09 & $24157-81-1$ & $N L$ & 150 & & $\mathrm{~B}$ & - & $<0.31(\mathrm{LOQ})$ \\
\hline Tridecyl prop-2-enoate & 21.19 & $3076-04-8$ & $N L$ & & I & B & - & $\checkmark$ \\
\hline 3-methylheptadecane & 21.48 & $6418-44-6$ & $N L$ & & I & B & - & $\checkmark$ \\
\hline $\begin{array}{l}\text { 3,5-di-tert-butyl-4- } \\
\text { hydroxybenzaldehyde }\end{array}$ & 21.50 & $1620-98-0$ & $N L$ & & II & A & $<0.48(\mathrm{LOQ})$ & $<0.48(\mathrm{LOQ})$ \\
\hline Butylhydroxytoluene $e^{b, d}$ & 21.54 & $128-37-0$ & 3 & & & A & $1.80 \pm 0.20$ & $<0.39(\mathrm{LOQ})$ \\
\hline Benzene, $1,1^{\prime}-(1,2-$ & 22.08 & $7694-30-6$ & $N L$ & & III & A & $\checkmark$ & $\checkmark$ \\
\hline cyclobutanediyl)bis-,cis- & & & 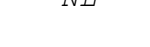 & & & B & - & $\checkmark$ \\
\hline $\begin{array}{l}\text { Trans-1,2-diphenylcyclo } \\
\text { butane }\end{array}$ & 22.10 & $20071-09-4$ & $N L$ & & III & $\mathrm{A}$ & - & $\checkmark$ \\
\hline $\begin{array}{l}\text { Phthalic acid, hept-4-yl } \\
\text { isobutyl ester }\end{array}$ & 22.12 & NIST356783 & $N L$ & & I & A & $\checkmark$ & - \\
\hline $\begin{array}{l}\text { 3-phenylpropyl, 3-phenyl } \\
\text { propanoate }\end{array}$ & 22.15 & $60045-27-4$ & $N L$ & & I & A & $\checkmark$ & - \\
\hline $\begin{array}{l}\text { Naphthalene, } 1,2,3,4- \\
\text { tetrahydro-1-phenyl }\end{array}$ & 22.31 & $3018-20-0$ & $N L$ & & III & A & $\checkmark$ & $\checkmark$ \\
\hline Isopropyl myristate ${ }^{d}$ & 22.59 & $110-27-0$ & $N L$ & & I & $\mathrm{A}$ & - & $\checkmark$ \\
\hline
\end{tabular}




\begin{tabular}{|c|c|c|c|c|c|c|c|c|}
\hline $\begin{array}{l}\text { 3-methyl-3-phenyl } \\
\text { azetidine }\end{array}$ & 22.76 & $5961-33-1$ & $N L$ & & III & A & - & $\checkmark$ \\
\hline $6,10,14$-trimethyl & & & & & & A & - & $\checkmark$ \\
\hline pentadecan-2-one & 22.82 & $502-69-2$ & $N L$ & & II & B & - & $\checkmark$ \\
\hline 1 -hexadecanol $1^{\mathrm{b}, \mathrm{d}}$ & 23.17 & $36653-82-4$ & ${ }_{-}^{c}$ & & & B & - & $140.30 \pm 1.50$ \\
\hline $\begin{array}{l}\text { Methyl 2-hydroxy- } \\
\text { heptadecanoate }\end{array}$ & 23.19 & NIST336201 & $N L$ & & II & A & - & $\checkmark$ \\
\hline Methyl palmitate ${ }^{b}$ & 23.63 & $112-39-0$ & $N L$ & & I & $\begin{array}{l}\text { A } \\
B\end{array}$ & $\begin{array}{c}<0.04(\mathrm{LOQ}) \\
-\end{array}$ & $<0.04(\mathrm{LOQ})$ \\
\hline Hexadecanoic acid & 23.96 & $57-10-3$ & ${ }_{-}^{c}$ & & & $\begin{array}{l}\text { A } \\
B\end{array}$ & $\begin{array}{l}- \\
-\end{array}$ & $\checkmark$ \\
\hline $\begin{array}{l}\text { Benzoic acid, 4-(trans-4- } \\
\text { butylcyclohexyl) 4-butoxy- } \\
\text { 2,3-dicyano phenylester }\end{array}$ & 24.17 & $75941-90-1$ & $N L$ & & & $\begin{array}{l}\text { A } \\
\text { B }\end{array}$ & - & $\begin{array}{l}\checkmark \\
\checkmark\end{array}$ \\
\hline & 24.33 & $88-29-9$ & $N L$ & 3 & & A & - & $\checkmark$ \\
\hline $\begin{array}{l}\text { tetramethyl tetralin } \\
\text { Hexadeca-9-en-1-old }\end{array}$ & 25.15 & $64437-47-4$ & $N L$ & & I & $\begin{array}{l}\mathrm{B} \\
\mathrm{B}\end{array}$ & - & $\begin{array}{l}\checkmark \\
\checkmark\end{array}$ \\
\hline & & & & & & A & - & $\checkmark$ \\
\hline Linoleic acid & 25.63 & $60-33-3$ & $-{ }^{c}$ & & & B & - & $\checkmark$ \\
\hline Bis (2-ethylhexyl) maleate & 25.74 & $142-16-5$ & $N L$ & & I & A & - & $\checkmark$ \\
\hline Octadecanoic acid & 25.82 & $57-11-4$ & ${ }_{-}^{c}$ & & & A & - & $\checkmark$ \\
\hline Tributyl citrate & 26.06 & $77-94-1$ & $\overline{N L}$ & & III & B & - & $62.10 \pm 1.64$ \\
\hline Pimaral & 26.51 & $472-39-9$ & $N L$ & & III & A & & $\checkmark$ \\
\hline Acetyltributyl citrate ${ }^{b, d}$ & 26.63 & $77-90-7$ & $32^{\mathrm{a}}$ & & & B & $39.35 \pm 1.25$ & $1942.5 \pm 414.9$ \\
\hline Dehydroabietal & 27.13 & $13601-88-2$ & $N L$ & & I & A & - & $\checkmark$ \\
\hline Pimaric acid & 27.40 & $127-27-5$ & $N L$ & & III & A & - & $\checkmark$ \\
\hline $\begin{array}{l}\text { 5-methyl-5- }(4,8,12- \\
\text { trimethyltridecyl) oxolan- } \\
\text { 2-one }\end{array}$ & 27.55 & $200272-61-3$ & $N L$ & & III & A & - & $\checkmark$ \\
\hline Methyl dehydroabietate & 27.65 & $1235-74-1$ & $N L$ & & I & $\begin{array}{l}\text { A } \\
B\end{array}$ & - & $\begin{array}{l}\checkmark \\
\checkmark\end{array}$ \\
\hline $\begin{array}{l}\text { 1,2-diphenylprop-2-en- } \\
1 \text {-one }\end{array}$ & 28,02 & $4452-11-3$ & $N L$ & & III & A & - & $\checkmark$ \\
\hline Dehydroabietic acid & 28,44 & $1740-19-8$ & $N L$ & & I & $\begin{array}{l}\mathrm{A} \\
\mathrm{B}\end{array}$ & - & $\begin{array}{l}\checkmark \\
\checkmark\end{array}$ \\
\hline
\end{tabular}


$N L$ not listed in Regulation 10/2011; ${ }^{a}$ SML (T) (group restriction); ${ }^{b}$ Confirmed with standards; ${ }^{C}$ Without Specific migration limit | (60 $\mathrm{mg} / \mathrm{kg}$ as limit of global migration limit applies). Identified in cardboard-cups and simulants. 


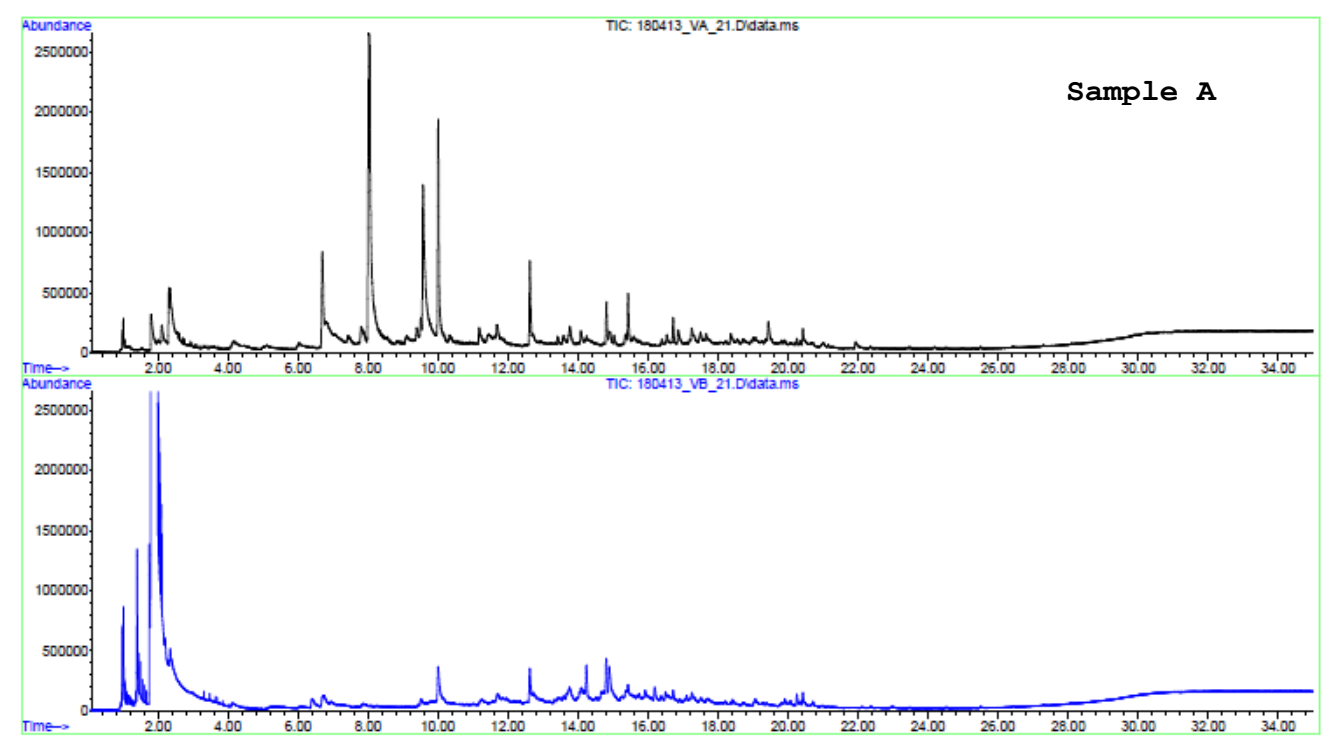

Fig. 1. Chromatograms obtained by HS-SPME-GC-MS (DVB/CAR/PDMS fiber and HP-5MS capillary column) for cardboard-cups samples A and B. 